INTERNATIONAL JOURNAL OF LIBRARIANSHIP, 6(2), 1-2.

ISSN: $2474-3542$

\title{
The Future is Here! Embracing a New Era of Open Platforms
}

Wei Liu, Deputy Director of Shanghai Library and Institute of Scientific and Technological Information of Shanghai, China

Tom Cramer, Associate University Librarian, Director of Digital Library Systems \& Services, Chief Technology Strategist, Stanford University Libraries, U.S.A

The library industry has never been closer to its vision than it is today, and never has it faced greater challenges than it does today.

We marvel at S. R. Ranganathan's "Five Laws of Library Science": Books Are For Use, Every Reader His/Her Book, Every Book Its Reader, Save The Time Of The Reader, and The Library Is A Growing Organism (Ranganathan, 1931). These five laws, full of idealism, have long seemed to be only a dream.

It is only today, with the development of information technology and the age of Artificial Intelligence, that this vision has become a reality. We are approaching Jorge Luis Borges' view that "Paradise will be a kind of library."

Without the advances of Big Data and Machine Learning, we could not break the 80/20 rule and find niche readers for long-tail books; we could not achieve precise targeting of our services or our collections; we could not optimize acquisition through user participation. It would never be possible to turn libraries into "data hubs" or even "knowledge repositories" without data-driven knowledge services.

All these developments depend on the support of a trans-media lifecycle process and web scale platforms. We must break away from traditional systems that focus only on the library's own business while ignoring the diverse needs of readers and users. Instead, we must use diverse techniques and disparate data sources to meet increasingly "high touch" user experience requirements.

A contemporary library platform must not integrate the traditional librarians' work modules such as acquisition, cataloging and circulation, but must become a platform for all library workflows; must not be satisfied with mastering eighteen individual of martial arts, but must become a Swiss Army knife; must not be a closed-door and self-contained system, but should be part of an open application ecosystem. There should be individual apps that can meet need of librarians and readers; there should even be apps that allow similar institutions, such as museums, art galleries, archives, and cultural centers, to be connected and integrated.

We are seeing the dawn of the ideal library, the sunlight that cloud-native technology and open source software are about to shine on the earth. An open platform led by the library industry will enable libraries to take full control of their data, make the most use of it, own their platform 
completely, all at a low cost. This platform will allow everyone to participate in developing and making continuous progress, allowing every company to become a library partner, allowing different vendors to hook up, plug and play, and be interchangeable with each other. In this future, all kinds of data and modules of libraries can be shared naturally and will be interconnected of course. Libraries will no longer depend on individual suppliers, and the security of library data can be fully guaranteed, and the future of libraries will be completely in their own hands, thus benefiting readers and the whole society!

This platform has now emerged, and it is the one, and the only: FOLIO - "Future Of Library Is Open!"

\section{References}

Ranganathan, S. R. 1931. The Five Laws of Library Science. London: Edward Goldston, Ltd.

\section{About the authors}

Liu Wei (Keven) is the Deputy Director of Shanghai Library and Institute of Scientific and Technological Information of Shanghai. He is also an adjunct professor of Fudan University, East China Normal University and Shanghai University, acts as a doctoral tutor and gives lectures on Digital Libraries and Digital Humanities. He took part in many major Digital Library projects in China since 1995. He is in charge of the information technology application in Shanghai Library and very active in developing "Smart Library" services for the Library. He is also the Vice Chairman of Shanghai Library Society, and member of the Governing Board of Dublin Core Metadata Initiative (DCMI).

Tom Cramer is the Associate University Librarian, Director, Digital Library Systems \& Services, Chief Technology Strategist at Stanford University. Tom is the founder and the Acting Managing Director of the International Image Interoperability Framework (IIIF) and serves as the Chair of its Coordinating Committee. He is also a founder and leader of Samvera (aka the Hydra Project); a catalyst and leader for Fedora 4 and founding member of the Fedora steering group; and the first adopter and an active contributor to Blacklight. Cramer is also Vice Chair on the DuraSpace Board of Directors; a steering group member of the International Internet Preservation Coalition; Chair and Co-Director of PASIG (Preservation and Archiving Special Interest Group); a member of the VIVO Leadership Group; and a former steering group member and past Program chair of Open Repositories. 